\title{
LOCALIZACIÓN DE VIDEOJUEGOS: PARATEXTOS MATERIALES E ICÓNICOS
}

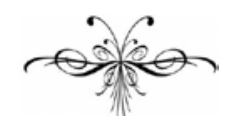

\author{
RAMÓN MÉNDEZ GONZÁLEZ
}

Resumen: El sector de los videojuegos es, a efectos académicos y profesionales, apenas un sector recién nacido con muchos recovecos desconocidos todavía por explorar. Son pocos los estudios en el ámbito de la traducción y la interpretación que profundicen en este sector y muchos profesionales desconocen todas las dinámicas que se están siguiendo en la práctica profesional de la localización. En este artículo definiremos la noción de localización, con el significado tan amplio que el propio término posee, para posteriormente presentar dos claros ejemplos de localización que están presentes en el día a día del sector pero de los que muy pocos son conscientes.

Palavras-chave: Videojuegos. Localización. Traducción. Paratraducción. Héroes.

\begin{abstract}
From an academic and professional perspectives the video game industry is just a newborn industry with many unknown nooks still to be explored. Few studies in the field of translation and interpretation have examined this industry more deeply, and many professionals do not know all the dynamics involved in their localization practice. In this article we will define the notion of localization in as broad a manner as the term accepts and we will offer two clear instances of localization that are present in the everyday activities of the industry, but of which few are aware.
\end{abstract}

Keywords: Videogames. Localization. Translation. Paratranslation. Heroes. 
$\mathrm{E}$ 1 mercado de los videojuegos es un sector en pleno auge y constante crecimiento. Lo que hace unos años parecía ser casi un sector minoritario y desconocido, en el que solo unos pocos parecían tener interés, se ha convertido en un importante fenómeno de ocio que genera unos ingresos que pueden incluso dejar en evidencia a los de otros sectores como el cine o la música. La propia evolución de los videojuegos como medio para contar historias ha permitido que lleguen al mercado cada vez más títulos con tintes cinematográficos, que comparten estantería con las producciones más sencillas y directas en las que el argumento pueda tener menos relevancia. A día de hoy hay juegos para todos los gustos y para todos los públicos, hasta el punto de que cualquiera puede encontrar un producto que se adapte a sus necesidades personales, por exigentes que estas puedan ser. Pero todos ellos tienen un elemento común: el producto debe ser localizado a los diferentes mercados para que el máximo número de usuarios posibles pueda tener acceso a él y disfrutarlo en condiciones. De esto no solo se beneficiará el gran público, sino también el propio sector, que ha visto cómo, desde que se empezaron a localizar los juegos de forma habitual, las ventas han aumentado de forma exponencial.

Se aproxima el momento de dejar atrás todos los tópicos y las concepciones erróneas y dar un salto definitivo hacia el gran público, consolidándose como un nuevo modelo artístico que pueda ser reconocido a nivel social y cultural. Lo que antaño parecía una utopía está más próximo que nunca, y así lo demuestra la acogida cada vez mayor que el ocio electrónico tiene en los hogares de todo el mundo. Sin embargo, ese empujón definitivo debe estar apoyado por un elemento tan crucial como es la traducción; independientemente del país del mundo, es necesario que los videojuegos hablen la misma lengua que su público para terminar de consolidarse.

(Méndez González, 2010: en red)

Pero, ¿qué significa localizar exactamente? Por norma general, cuando se habla de localizar un videojuego, mucha gente piensa automáticamente en la fase de traducción, en trabajar con el texto sin tener en cuenta la imagen o todos los elementos que acompañan al texto. Pero en un videojuego existe una relación intersemiótica en la que la pareja texto-imagen no es una mezcla fusionada ni un conjunto híbrido, sino que ambos mantienen sus identidades semióticas sin renunciar a las mismas, gracias al mestizaje estético y semiótico de lo textual y lo icónico. Esta nueva entidad iconotextual que se forma es una entidad mixta, donde el elemento verbal está presente al 100\% y el elemento visual también está presente al 100\%, con una perfecta armonía entre ambos (Yuste Frías, 2006: 269-272). Es por eso mismo que nos encontramos con un tipo de texto completamente novedoso y diferente, en el que se deben afrontar dinámicas particulares en las que se tengan en cuenta todos y cada uno de los elementos, tanto textuales como paratextuales, que componen una producción videolúdica (cf. Ramón Méndez, 2012a).

El término «localización» abarca todo, desde los elementos textuales contenidos dentro del propio juego hasta las carátulas, la publicidad, los aspectos culturales o incluso los elementos sonoros. La localización es todo proceso de adaptar lingüística y culturalmente un producto, en cualquiera de sus epitextos o peritextos, a mercados diferentes. Dicho de otra forma, localizar es un término cuya definición bien podría ser «traducir y paratraducir todo producto audiovisual y multimedia mediante los textos y sus correspondientes paratextos que lo acompañan, 
lo rodean, lo envuelven, lo prolongan, lo introducen y lo presentan tanto en pantalla como fuera de ella». Por eso mismo, este estudio se ha desarrollado bajo el prisma de la traducción y la paratraducción, porque es el único enfoque posible para comprender plenamente cómo funciona el mundo de los videojuegos y, por tanto, ser capaces de realizar una buena labor a la hora de localizar un producto y de ofrecer a los usuarios de culturas diferentes ese objetivo principal de toda producción de ocio electrónico: sumergirlos en la pantalla y lograr que la virtualidad y el baño de imágenes les permita sentirse parte de la aventura que están viviendo.

(Méndez González, 2012a: 21)

\section{Localizar el mando de control}

Un elemento crucial y fundamental en todo videojuego, independiente de la plataforma para la que se lance, es el mando de control. A lo largo de la historia han salido al mercado un gran abanico de mandos, según la consola, y los usuarios han mostrado sus preferencias ante unos u otros según la comodidad, las opciones de control que le oferten o su accesibilidad. No en vano, son muchas las horas que se pueden invertir ante la pantalla dejando que todas nuestras acciones pasen por dicho mando de control, por lo que, para lograr sumergir completamente al jugador en la imagen que se le presenta en pantalla, es preciso lograr la fusión entre la mano del usuario y el mando.

Muchas veces tendemos a caer, nosotros y las propias compañías de hardware,
en el funesto error de hablar únicamente de microprocesadores, de potencia grá-
fica, de chips de sonido, olvidándonos de lo importante y vital que puede ser un
"simple” mando a la hora de enganchar al usuario a la consola como si de un
cordón umbilical se tratara. Pixfans (2009)

De todos los mandos de control que se han lanzado al mercado hasta la fecha, el que mejor ha comprendido el mercado internacional y mejor se ha adaptado a las necesidades de los usuarios de todo el mundo ha sido el de PlayStation. A diferencia de otros mandos, que apostaban por letras y colores, Sony se la jugó todo por una simbología icónica que se convertiría en seña de identidad de la marca. Pero no solo eso, sino que tiene un sentido coherente la elección de las formas geométricas que presentan los botones. Aunque el análisis del mando completo es motivo de un estudio más completo que no tiene cabida en el presente artículo (pero que se puede encontrar en Méndez González, 2012a), hoy nos quedaremos con los dos botones del mando (el botón X y el botón Círculo) que se convierten en el ejemplo perfecto de que cultura, iconografía y colores no son universales en ningún ámbito del conocimiento humano. 


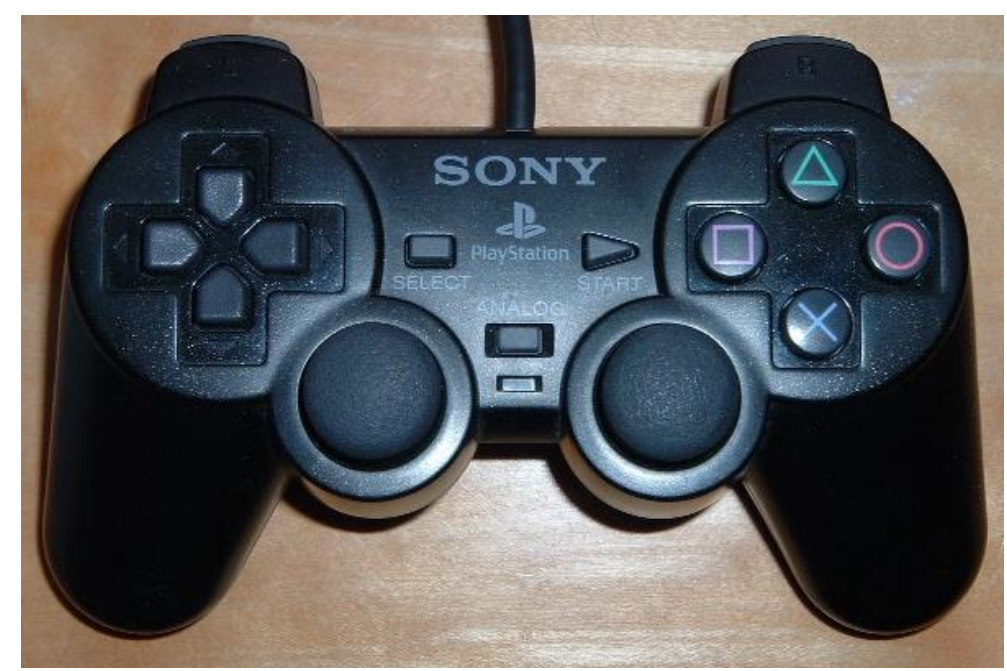

Dentro del significado simbólico, un círculo suele indicar algo correcto o que se acepta, mientras que una equis suele usarse para destacar algo erróneo o que se debe cancelar. Sin embargo, a la hora de ponerse ante un juego con un mando en las manos, históricamente el botón inferior ha sido siempre el de aceptar y el del lado derecho el de cancelar. Incluso los colores se contradicen con la simbología, ya que el azul es un color que suele interpretarse como algo bueno o algo aceptado, mientras que el rojo suele ser sinónimo de lo malo y de lo que está prohibido. Pero todo tiene una explicación, tal y como hemos podido constatar en nuestra investigación, y es que mientras para nosotros (occidentales, es decir, europeos y americanos) esa es la disposición normal de los botones, para Japón es justamente al revés: desde siempre, en tierras niponas se acepta con el botón del lado derecho y se cancela con el botón inferior. Algo que, incluso en la propia localización de los videojuegos, obliga a los desarrolladores a modificar el código a nivel profundo para adaptarlo a este cambio cultural indispensable para que el producto funcione en otros mercados (de hecho, en los pocos juegos en los que no se ha cambiado, se ha conseguido generar desconcierto en los usuarios y hasta parecía una simple señal de extravagancia por parte del creador).

Si nos alejamos de la marca PlayStation y observamos otros mandos de otras compañías, se puede ver la tendencia y el choque cultural que suponen los códigos de colores de un mercado a otro.

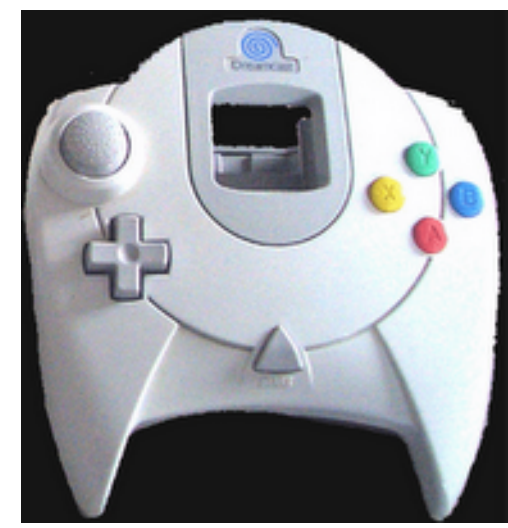

Dreamcast

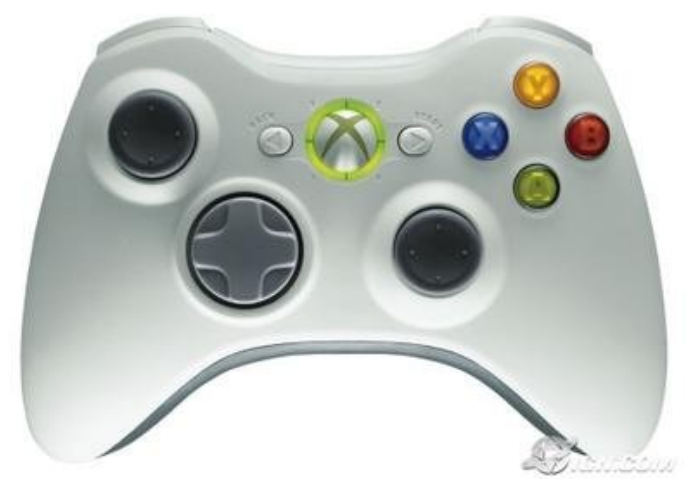

Xbox 360 
A la izquierda nos encontramos con un mando de Dreamcast desarrollado por Sega en Japón. Siguiendo la tónica comentada hasta ahora, se emplea un código de colores en el que el azul se sitúa en el botón de la derecha, mientras que el rojo se sitúa en el lado inferior del mando. Desde nuestro punto de vista europeo (Yuste Frías, 2009) el azul es nuestro color preferido, sea cual sea el sexo, la clase social, la profesión o el nivel cultural. El azul, en la simbología occidental sugiere calma y tranquilidad, con él se indica todo aquello que se autoriza, da confianza, promueve la paz y las alianzas de civilizaciones; por eso es el color de los códigos de circulación y de diversos organismos internacionales. Por el contrario, el rojo señaliza los peligros y prohibiciones, por lo que es hasta cierto punto una incongruencia el gozar de esta disposición fuera del territorio nipón. En la ínsula japonesa, el botón B azul supone aceptar, mientras que el botón A rojo implica cancelar. En el resto del mundo, es exactamente al revés, y se sigue haciendo la fuerza de la inercia de un movimiento aprendido desde los inicios de los videojuegos. La propia Sega ha sido consciente de ello en su momento, y para tal fin, aunque el mando se mantuvo inalterado por motivos comerciales y de diseño dentro de los propios juegos (las complicaciones de marketing, programación, promoción y adaptación de los títulos a dos tipos de mando diferentes supondría unos costes descomunalmente elevados), sí que adaptó el logotipo de su máquina a los colores favoritos de cada región, utilizando el rojo en Japón y el azul en el resto del mundo. Porque, como ya hemos comentado, el azul es el color preferido en occidente, mientras que en Japón dicho honor le corresponde al rojo:
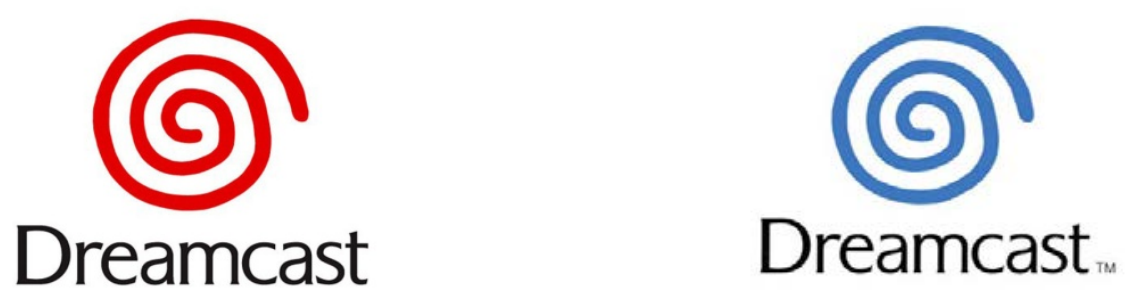

Sin embargo, desde Norteamérica, Microsoft ha diseñado un mando (cuadro superior, derecha) en el que el botón A de aceptar presenta un color verde mientras que el botón $\mathrm{B}$ de cancelar es de color rojo. Sobre este último no volveremos a incidir, sino que nos centraremos en analizar por qué es acertada la elección del color verde como botón de aceptar. El verde es un color de equilibrio, relacionado con la esperanza, la razón, la lógica y la juventud, sugiere frescura y primavera, y se asocia con todo aquello a lo que se da una aprobación. No en vano, a los proyectos se les da luz verde, los tests y cuestionarios online acertados o completos se representan con un tick verde, o incluso en el semáforo el verde es el color que permite pasar y avanzar sin riesgos, mientras que el rojo nos obliga a detenernos y tener cuidado ante los peligros que podemos encontrarnos de violar su código.

Aquí volvemos a encontrarnos una importante diferencia cultural entre oriente y occidente, ya que si bien en occidente los usuarios se acostumbran y aceptan un intercambio ideológico en la presentación y colocación de los botones, los nipones son un mercado mucho más cerrado y que rechaza las nuevas ideas. Es por eso que las dos consolas de Microsoft, Xbox y Xbox 360, tuvieron y siguen teniendo grandes problemas para hacerse un hueco en el competitivo mercado japonés. En primera instancia, porque el patriotismo nipón les lleva a apoyar a sus compañías antes de darle una oportunidad a una marca extranjera; en segundo lugar, porque 
aunque se coloque la programación de los botones en el lugar deseado por los nipones, para ellos supone un choque cultural e ideológico importante el aceptar ese cambio del código de colores en sus mandos.

Sin embargo, volviendo al mando de PlayStation, ¿por qué se aceptó ese cambio de colores, en el que el rojo sirve para aceptar y el azul para cancelar? Según Goto, su creador, la gente le decía que los colores estaban entremezclados y él mismo tuvo que defender que era esa disposición del mando la que él quería. Lejos de ser un error o un capricho, Goto tenía muy bien pensado el cómo hacer llegar a todo el mundo un mando, fácilmente comprensible y aceptable por públicos de diferentes ideologías, culturas y formas de ver el mundo.

\begin{tabular}{l|l|l} 
& Japón & Mundo \\
\hline Botón X & Cancelar & Aceptar \\
\hline Boton Círculo & Aceptar & Cancelar \\
\hline Color azul (de la X) & Cancelar & Aceptar \\
\hline Color rojo (del Círculo) & Aceptar & Cancelar
\end{tabular}

Para empezar, la combinación de elementos hace que en todos los territorios algo concuerde y sea fácilmente reconocible por el usuario. Mientras para los occidentales el código de color es el correcto (el color prevalece sobre la forma), para los nipones, la iconografía es la adecuada (la forma prevalece sobre el color), pudiendo reaccionar tanto unos como otros de forma instintiva al botón del mando.

En Japón, la cruz y el círculo se llaman «batsu» y «maru» respectivamente, el primero muestra lo que no se debe hacer, significa siempre prohibición, algo incorrecto y mal hecho que no debe hacerse. Por su parte, "maru» es símbolo de aprobación, un círculo que puede occidentalizarse como la primera letra del anglicismo «OK». Tan importantes son ambos en el mundo nipón que no solo se utilizan en carteles y avisos de seguridad, sino que además los propios japoneses los han incorporado a su lenguaje corporal, cruzando los brazos para representar «batsu» o haciendo un círculo en torno a sus cabezas con ambos brazos, o simplemente haciendo el círculo con las manos, para transmitir «maru» (este segundo caso es menos común, aunque no del todo extraño).

Por tanto, este aspecto no se podía trastocar en la cultura nipona, que reacciona en este caso antes a la simbología de las formas que a la simbología de los colores. Además, al ser el rojo su color preferido, no desentona en exceso que sea el elegido para representar la aprobación, aunque no sea el ideal. En cambio, el usuario occidental suele adaptarse mejor a las características diversas que han ofrecido los mandos de consola a lo largo de la historia y, por tanto, tiene una mayor versatilidad para adaptarse a un cambio iconográfico a cambio de poder abrazar un código de colores que comprende y tiene sentido para él. La labor de Goto con el mando de PlayStation ha sido, a todas luces, un concienzudo estudio paratraductor para conseguir solventar las discrepancias habituales en los diferentes mandos a lo largo de la historia, y a juzgar por el éxito de las cuatro versiones de la máquina hasta la fecha (más dos portátiles), no cabe duda de que ha sabido leer muy bien las muy dispares culturas del planeta.

Tal es la disparidad y las particularidades del mercado nipón que, tal y como ya hemos comentado, Microsoft está teniendo importantes problemas a la hora de intentar llegar a un público que, pese a los esfuerzos económicos que se están realizando, no se llega a conocer a nivel profundo. El importante desconocimiento 
de la cultura, las formas de pensar y de vivir e incluso las costumbres niponas provocan que la compañía de Redmond cometa errores de principiante al no saber dar ese paso más allá y paratraducir sus productos a un mercado que, les guste o no, es muchísimo más diferente del suyo de lo que les gustaría. Comentamos esto hablando de mandos porque precisamente uno de los errores fundamentales cometidos por la compañía norteamericana nos los encontramos en el propio mando de control de su primera máquina, Xbox. Esta, en un primer momento, se distribuyó en todo el mundo con un mando de dimensiones más que considerables, prácticamente de la mitad del tamaño de la propia consola, algo excesivo pero que en un principio no molestaba a muchos.

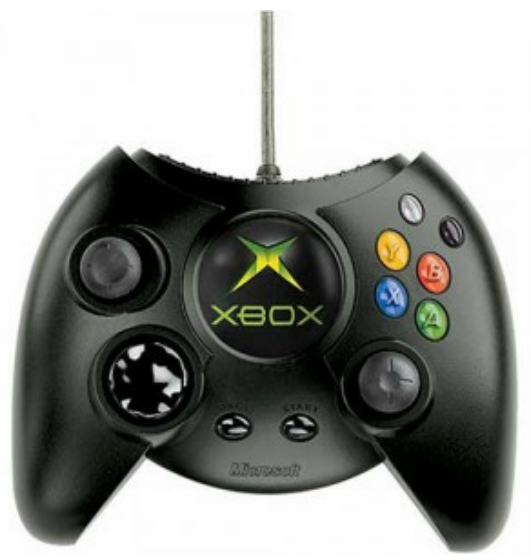

Sin embargo, hubo una barrera que no perdonó los errores y problemas de este mando de grandes dimensiones: el mercado japonés, que no dudó en mostrar su rechazo desde el primer día y obligó a Microsoft a llevar a cabo una revisión de su mando de control, porque tal y como dijo Bill Gates en su día en la presentación del nuevo producto, no todos los usuarios tienen las manos del mismo tamaño, así que para mercados como el nipón era preciso ofrecerles un mando apto para usuarios con las manos más pequeñas. Así pues, apenas unos meses después del lanzamiento de la consola, se desarrolló un nuevo mando de control más pequeño, enfocado fundamentalmente para el mercado japonés.

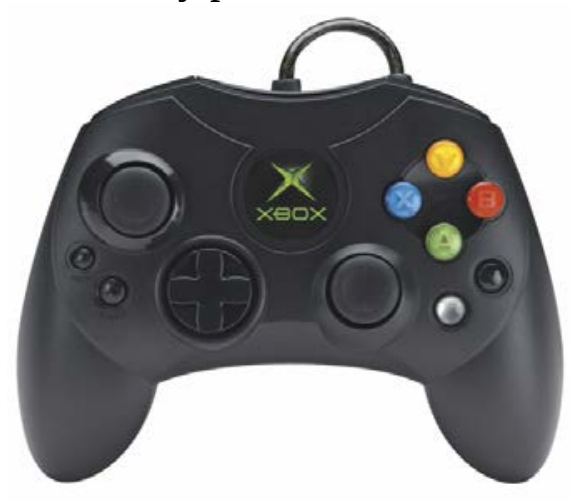

Lo que no tuvo en cuenta el gigante norteamericano es que no solo era tarde para aquel movimiento, ya que la consola ya se había convertido en una plataforma demasiado impopular en el país nipón, sino que además se había insultado el honor de todos los habitantes de la isla con un comentario aparentemente inocente pero vejatorio a varios niveles, sobre el tamaño de las manos de los habitantes del país, creando así una distinción entre mercados que desprestigiaba a los nipones an- 
te el resto del mundo. Microsoft, incapaz de percatarse de dónde estaba el error de base de su política, intentó minimizar los efectos de este inocente desprecio expandiendo este nuevo mando al resto de los mercados, donde para sorpresa de los de Redmond también fue acogido con más éxito que el mando original.

Este ejemplo demuestra que actuar sin pensar antes, sin tener muy en cuenta todas las particularidades y características propias de cada uno de los mercados a los que se intenta llegar, acaba suponiendo un sonoro fracaso. No se puede negar que Sony, a diferencia de muchas de sus competidoras, supo comprender el mercado y utilizar culturemas e ideogramas que, ya desde el propio hardware, transmitía por igual mensajes y sensaciones a los usuarios de todo el mundo. Un trabajo paratraductivo que se ve fuera de la pantalla y que se convierte en uno de los elementos fundamentales para el éxito comercial en todo el mundo: la creación de una imagen, una marca, que sea universal.

\section{Localizar a los héroes}

Las diferencias culturales entre oriente y occidente no se limitan solo a la producción paratextual de dispositivos y elementos fuera de la pantalla, sino que también se plasman dentro de la misma. Especialmente curioso es el caso de los héroes protagonistas, ya que la percepción del personaje principal es muy distinta según el mercado en el que nos encontremos.

En las versiones norteamericanas suelen triunfar los héroes fuertes y aguerridos, guerreros cargados de músculos cuya sola presencia ya intimida al enemigo, el cual no suele presentar signos de debilidad precisamente y puede presentarse también como una masa cargada de esteroides. Pongamos por ejemplo al héroe americano por excelencia, Superman, quien destaca por su gran fuerza física, la cual se hace notar tanto en la potencia de sus golpes como por los marcados músculos; de hecho, uno de los autores más consagrados del panorama del cómic norteamericano, Rob Liefeld, se ha hecho famoso por su casi enfermiza obsesión por crear personajes excesivamente musculados. Por su parte, los héroes japoneses suelen ser más bien delgados, de habilidades especiales que no demuestran a simple vista, con un cierto toque andrógino en muchas ocasiones. Por poner un ejemplo, héroes nipones ya casi atemporales como Naruto o los caballeros del zodíaco nos presentan a personajes que, pese a luchar por potenciar sus habilidades al máximo y demostrar su fortaleza a la mínima, no necesitan demostrar su superioridad en condiciones normales y parecen personas más humanas y mundanales.

Este detalle, que podría parecer desechable en un primer análisis, ha demostrado ser de vital importancia a la hora de conseguir que un producto triunfe o fracase dentro de un territorio concreto. Actualmente, se marcan dos tendencias claras en el mundo del desarrollo de videojuegos: la occidental y la oriental. Usaremos como caso de estudio principal Nier (2010), un título desarrollado por el estudio Cavia para Square Enix que se convierte en un claro caso de paratraducción del héroe según los mercados en los que vería la luz el producto.

NIER es el nombre con el que se conoce al juego en occidente, pero en Japón hubo dos entregas distintas: Nier Gestalt (Xbox 360, 2010) y NiER RePLICANT (PlayStation 3, 2010). El principal rasgo diferenciador de ambos juegos era artístico fundamentalmente: el protagonista principal en Xbox 360 era un hombre fuerte, musculado, con una gran espada, un maduro padre de familia que va en bus- 
ca de su hija la cual ha sido raptada; por su parte, el protagonista de la entrega para PlayStation 3 era un chico sencillo, con un leve toque andrógino, joven, un hermano que desea rescatar a su hermana secuestrada. Por lo demás, los juegos comparten las escenas de vídeo, argumento, combates... Tan solo se cambia al personaje principal y, como es lógico, algunas líneas de diálogo para que se reflejen textualmente los cambios en los diferentes argumentos.

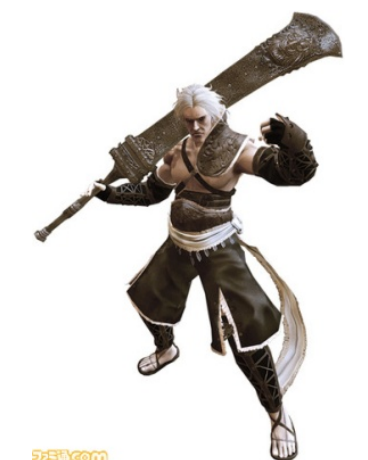

Nier en versión GESTALT

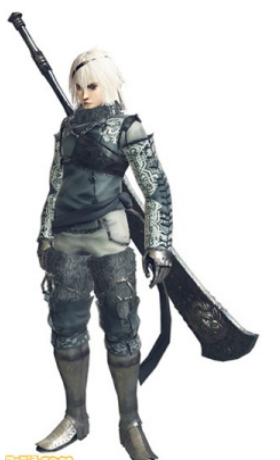

Nier en versión REPLICANT

Para muchos, estos cambios se antojaron excesivos e innecesarios, una manera de enajenar al público y al propio producto, pero lo cierto es que si se analiza la ingente producción de videojuegos anual se puede observar que no hay nada de mito en la búsqueda de un héroe con el que los distintos públicos se puedan identificar, ya que las identidades nacionales juegan un papel crucial a la hora de sentirse identificados con un personaje principal. De hecho, NIER fue el primero de los títulos de Square Enix en seguir ese proceso occidentalizador, ya que la compañía nipona está empezando a abandonar su tradicional modelo de negocio para beneficiar a cambio al público internacional. Sus análisis de mercado son exhaustivos y, en septiembre de 2010, Yosuke Shiokawa, director creativo de la compañía, ha destacado que al principio comenzaron trabajando con una idea en mente, la de que para llegar al usuario occidental deberían ofrecerles personajes musculosos, tipos duros y con marcado estilo realista. No obstante, desde los estudios de desarrollo se dejaron oír voces que se quejaban de que esos personajes no resultaban nada interesantes a la hora de trabajar con ellos, junto con la duda de que el público estuviese realmente interesado en ese tipo de personajes. Así pues, los desarrolladores japoneses están empezando a cambiar su tendencia hacia el diseño de personajes creíbles, que el usuario pueda ver y sentirse identificado con ellos desde la primera toma de contacto.

Estos estudios provienen de los resultados obtenidos con este experimento que fue NIER. ¿Hasta qué punto es necesario cambiar el propio personaje central del videojuego para adecuarse al público potencial? Podría parecer innecesario, pero lo cierto es que las tendencias son bastante claras si se realiza un pequeño análisis de los héroes que protagonizan las producciones norteamericanas y japonesas: 


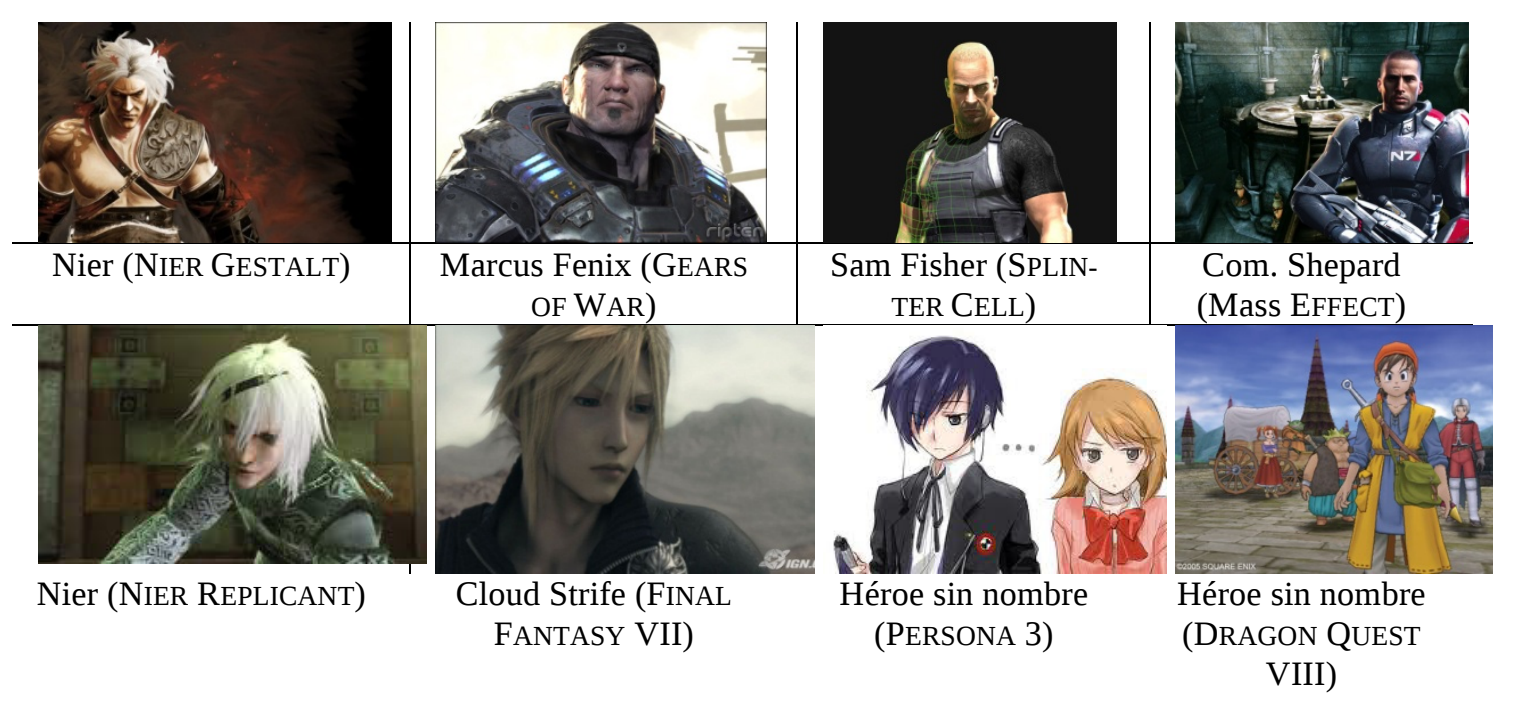

A simple vista se puede ver una clara diferencia entre los protagonistas habituales de producciones occidentales (hilera superior) y los héroes de los juegos nipones de mayor éxito (hilera inferior). Ya no es solo el estilo de vestimentas (con armaduras y tecnología en occidente, con ropas sencillas y trajes modestos que anteponen la estética a la utilidad en combate en oriente), sino los rasgos, el tipo de peinado, las expresiones faciales... Hay un costumbrismo muy marcado en los distintos territorios a la hora de enfocar el cómo debe ser un personaje, y viendo esta comparativa no se puede negar el gran acierto de Square Enix a la hora de saber leer el imaginario de héroe propia de cada mercado y así adaptar al héroe de esta producción a lo que cada uno espera de él.

¿Cómo transmitir al usuario nipón el mensaje, que pueda entender desde la estantería de la tienda, el espacio físico donde se presenta el producto, la diferencia del personaje? La respuesta de Square Enix ha sido la de crear portadas enfrentadas, protagonizadas única y exclusivamente por los héroes de cada aventura, protagonizadas además por los colores más habituales en las producciones de cada territorio: los marrones y rojizos occidentales frente a los grises y azules claros orientales.
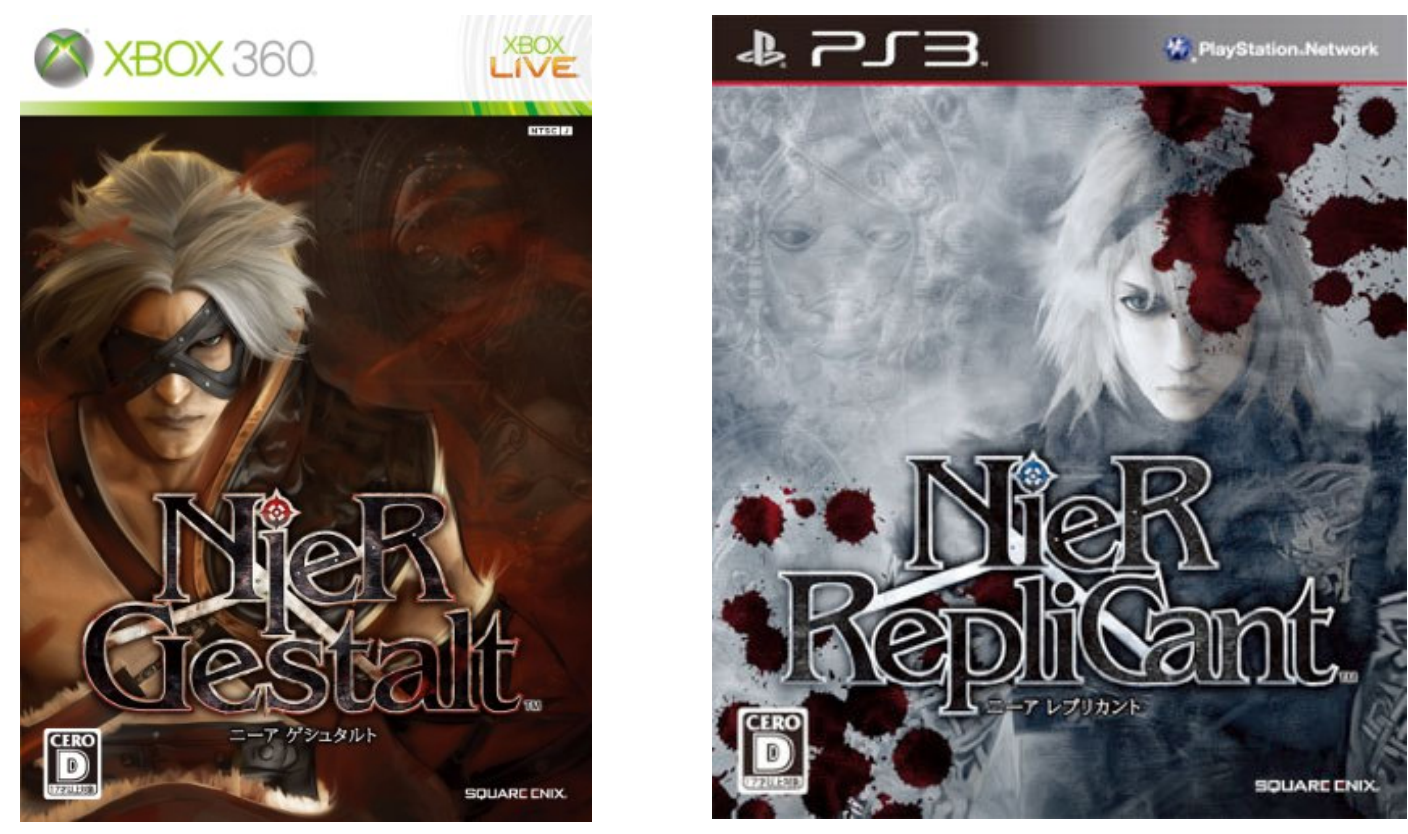


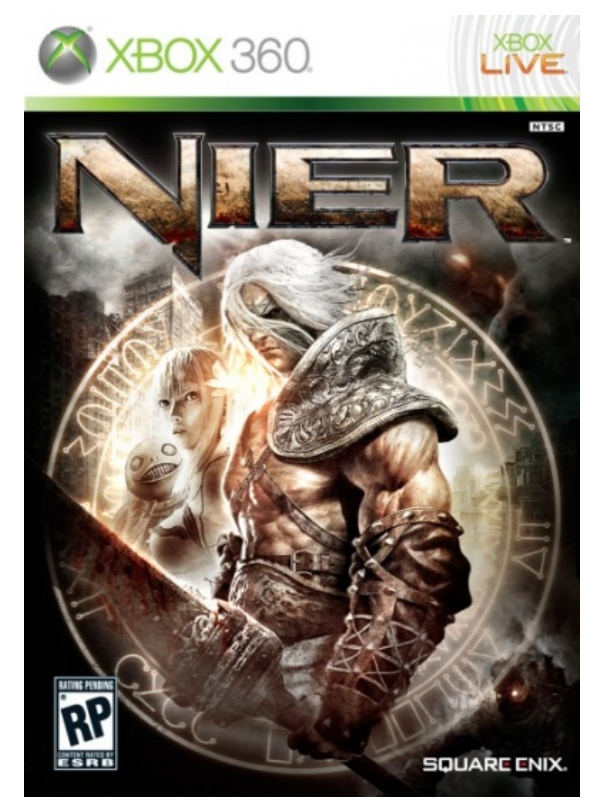

El resultado fue, desgraciadamente, caótico. El público no entendía bien por qué había dos entregas diferentes; ¿era solo el protagonista o cambiaban elementos de la aventura? ¿Había extras diferentes según el juego? ¿Qué cambios existían? Infinidad de preguntas que no se resolvían e, incluso durante las presentaciones del título, no se profundizaba demasiado en el tema de las diferencias, más allá de los matices argumentales y del cambio de protagonista. No obstante, desde el punto de vista paratraductivo, hay que elogiar a Square Enix por saber comprender y plasmar tan bien los mercados occidental y oriental, plasmarlo con tanta sencillez y precisión en una misma carátula vista desde dos prismas culturales completamente opuestos. Además, el juego occidental llegó al mercado exclusivamente para la plataforma Xbox 360, de origen norteamericano y bastante crucificada en el país nipón por asociarla con ese estilo de juegos que tan poco calado tienen entre el público japonés; por su parte, la versión oriental salió a la venta solo para PlayStation 3, la máquina patria, con la cual se asocian prácticamente todos los éxitos de Japón en el mercado de los videojuegos, que ayudó a crear una identidad propia a nivel internacional.

Pero esta dualidad no se vio reflejada lejos de la ínsula nipona. En Europa y Estados Unidos el juego presentaría una única versión, que sería como es lógico la occidental, es decir, la edición GESTALT, aunque ya eliminando ese subtítulo diferenciador dado que ya no tenía razón alguna de ser. Así pues, NiER llegaría a Xbox 360 y PlayStation 3 en una edición única en la que el protagonista sería un padre en busca de su hija. ¿Dónde queda la alternativa japonesa, del adolescente en busca de su hermana? Según las propias desarrolladoras, estas temáticas y planteamientos no tienen cabida en mercados fuera del oriental, y si se desea aumentar las ventas y llegar a públicos diferentes es necesario realizar una paratraducción de todos los elementos peritextuales presentes en el producto para adaptarlos a los culturemas, ideologías y costumbres propias del público receptor.

Media producers, from radio to video game designers, should be aware that whatever they produce is consumed by people with perceptions based on real life and quite often interpret at that way. If whatever they watch is in agreement with their beliefs (bad or otherwise), then it would reinforce such beliefs.

Eastin et. Al. (2009: 337-356)

Esta cita de Eastin es de gran importancia, sobre todo a la hora de transmitir el mensaje clave del producto al usuario desde la estantería de la tienda. Es por eso mismo que lo que hemos comentado en este caso de NIER no es algo aislado, sino que forma parte de una práctica extremadamente habitual desde el punto de vista comercial. No el que se modifique el propio juego, lo cual no deja de ser el siguiente paso en las acciones tradicionales, sino que los propios héroes y protagonistas de la carátula se localizan de forma sustancial según el territorio en el que se lance el juego. Y es que, tal y como afirma Eastin, la percepción de la gente es fundamental, y hay casos especialmente curiosos como el de CASTLEVANIA: LORDS of 
SHADOW (2010), un producto desarrollado en España, en el que se ofrecen dos tipos de portada diferentes. En primer lugar, la edición básica del juego, llega con una carátula bastante típica en la que el héroe, en su versión tridimensional, copa la carátula:

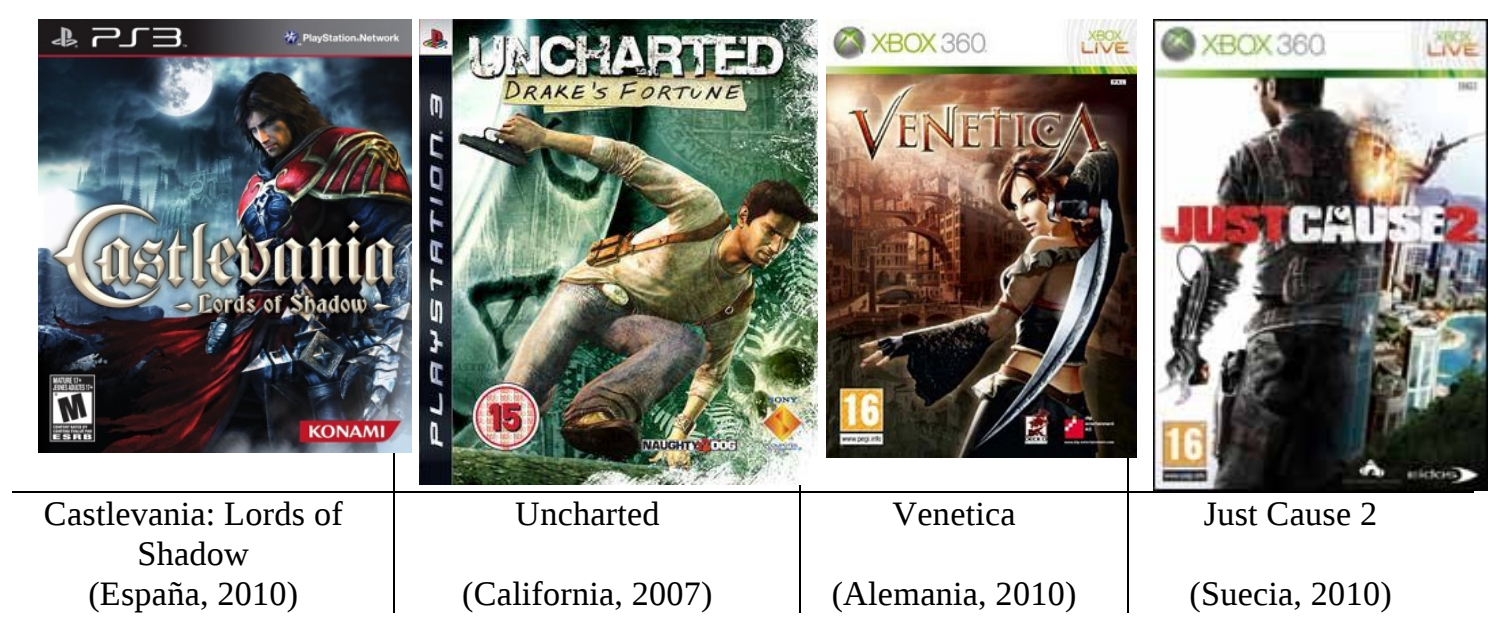

Como se puede observar, en la creación de carátulas occidentales se repiten una serie de elementos clave, independientemente del país de origen de los desarrolladores. Los títulos de acción, por lo general, siguen unas reglas fundamentales, no escritas, en las que el héroe debe estar en primer plano, en formato completamente tridimensional, con un fondo en el que se pueda ver el entorno más importante del juego y el título situado sobre toda la imagen, ya sea centrada o limitada a la esquina superior de la carátula con el fin de no entorpecer la visión del héroe principal de la aventura (el cual ya se suele situar incluso hacia la derecha de la imagen, para que los llamativos logotipos del PEGI no tapen al protagonista).

Pero como es lógico, esto no vale para todos los mercados, y mucho menos para el nipón en un caso como el de Castlevania. Pese a estar desarrollado en España, el título pertenece a la nipona Konami y es la trigésimo sexta entrega dentro de la franquicia hasta la fecha. Así pues, es preciso tener muy en cuenta al mercado inicial del producto, ese público nipón que ha apoyado la serie Castlevania durante las últimas dos décadas; para tal fin, existe una segunda versión de la carátula en la que el héroe se ve modificado para adaptarse mejor a lo que el público japonés se espera de una entrega de esta franquicia, para que reconozca fácilmente las señas de identidad presentes en la carátula cuando lleguen a la tienda.
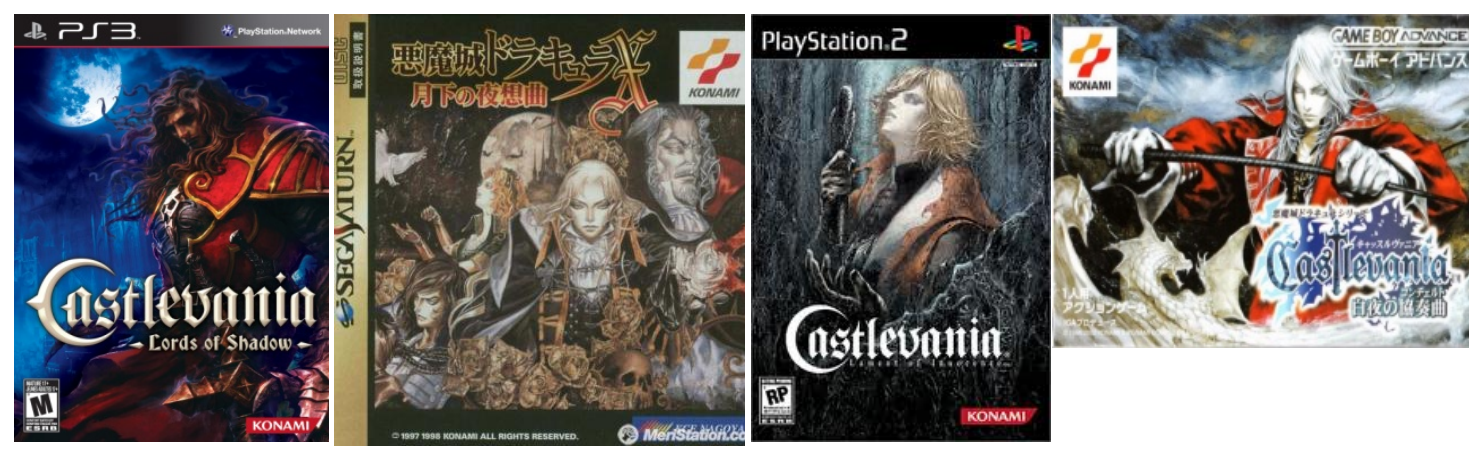
Desde hace más de una década, la franquicia CASTLEVANIA ha estado representada en Japón (y, en algunos casos, en el resto del mundo), por ilustraciones góticas y oscuras, recargadas y con toces lúgubres que hacen pensar en la oscuridad de la noche (momento en el que los vampiros inician su cacería), en las que se presenta al personaje principal y se recarga el fondo para lograr un acabado digno de la novela de Bram Stoker. Así pues, LORDS OF SHADOW se lanza también con una carátula en apariencia igual pero muy diferente a nivel profundo, ya que abandona la tridimensionalidad de la anterior para ofrecer una ilustración que sigue más la línea tradicional de los CASTLEVANIA nipones. Ya de paso, se modifican ligeramente algunos rasgos y características del personaje principal para adaptarse más a un estilo visual que el público nipón pueda reconocer con sencillez.

Pero esta dinámica de adaptación de los juegos a diferentes estilos artísticos de sus héroes no se limita solo a las producciones niponas, sino que tampoco es raro ver un cambio de estilo en producciones norteamericanas que desean llegar a triunfar en territorio nipón, como por ejemplo CRACKDOWN (2007).
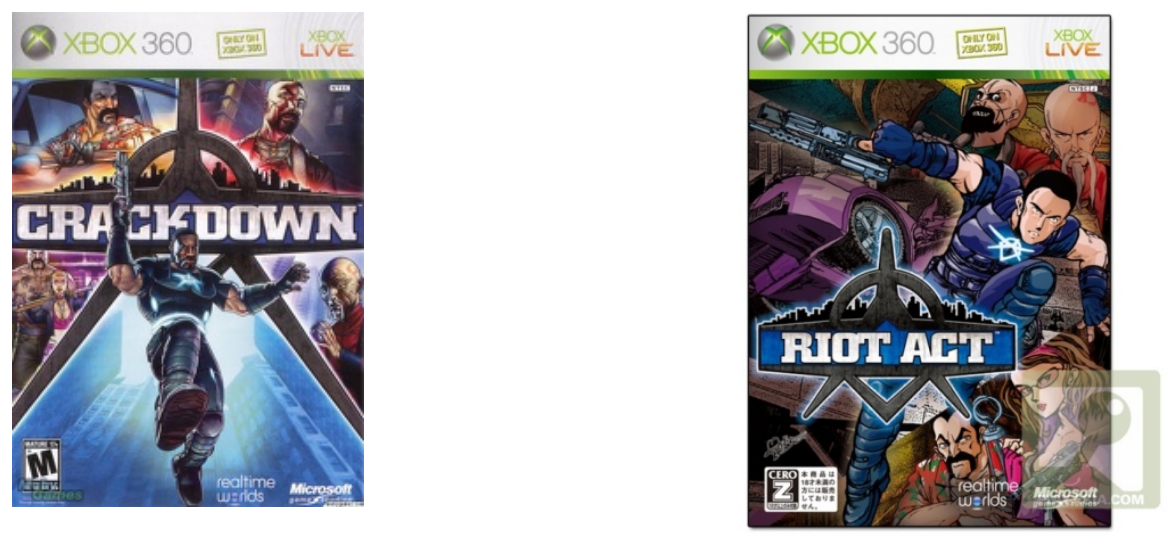

Nos encontramos aquí (además de un cambio de nombre por motivos legales) con una modificación sustancial, desde una tridimensionalidad occidental hacia un estilo de cómic que cala mucho mejor en el mercado nipón, generalmente reacio a los productos que destilan en exceso ese aura meramente digital. Destaca también cómo se mantiene la verticalidad, pero se logra el contraste al hacer que en la versión occidental sea descendente mientras que en la versión oriental se trata de una verticalidad ascendente. No solo eso, sino que además, pese a que el azul está presente en ambas imágenes, en la versión occidental es un color exageradamente predominante, ocupando y dominando aproximadamente una cuarta parte de la carátula. Los cambios son notables entre ambos productos pese a que, a grandes rasgos, se intentan mantener los mismos elementos básicos en ambos mercados.

Pero también existen movimientos más arriesgados, y volvemos al cambio de personajes, como el que ha hecho Capcom con una de sus franquicias estrella, DEVIL MAY CRY. Entre 2001 y 2008, Capcom desarrolló cuatro entregas de la misma, con un protagonista, Dante, que mantuvo inalterado su estilo y su personalidad. 


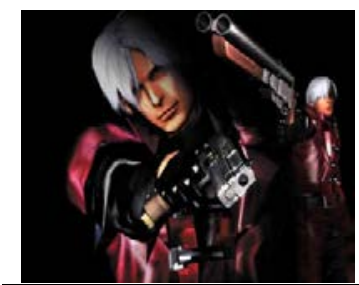

DEVIL MAY CRY (2001)

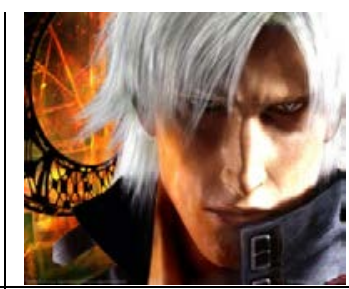

DEVIL MAY CRY 2 (2003)

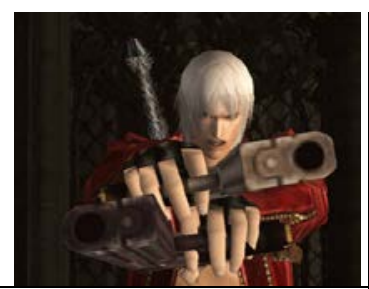

DEVIL MAY CRY 3 (2005)

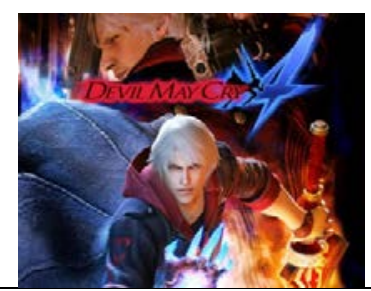

DEVIL MAY CRY 4 (2008)

Pelo blanco, chaqueta roja, una gran muestra de arrogancia y alardes... Dante se convirtió en un emblema en el mundo de los videojuegos, con serie de animación y merchandising variado. En 2010, Capcom anunció que quería hacer la serie más apta para el público occidental - de nuevo ese proceso occidentalizador que las compañías niponas están siguiendo a rajatabla en los últimos años - alegando en este caso Capcom que su franquicia necesitaba un toque occidental más fresco.

DEVIL MAY CRY 5 is a game that, when started development, this will change a lot in relation to the above. The reason is that, despite the Franchise has some very loyal followers, their sales are not particularly high, especially overseas. For this reason, it is likely that in the fifth chapter will incorporate certain 'Western touch' to make it more attractive to American and European players.

Keiji Inafune

El resultado fue la presentación de una nueva entrega que no sería desarrollada en Japón, como las anteriores, sino que correría a cargo del estudio británico Ninja Theory, y que contaría con una revisión completa del personaje, empezando por su aspecto y afectando a su personalidad (derecha). Las reacciones fueron instantáneas y muy negativas por parte de la comunidad, además de bastante escépticas por parte de la prensa especializada. Hay algunos rumores que sugieren que los propios directivos de Capcom querían causar un gran impacto que supusiese publicidad directa al título. Un juego que ya no sería DeviL MAY CRY 5, sino simplemente DmC, destacando el cambio de la franquicia hacia un terreno más aceptado, en teoría, por el público

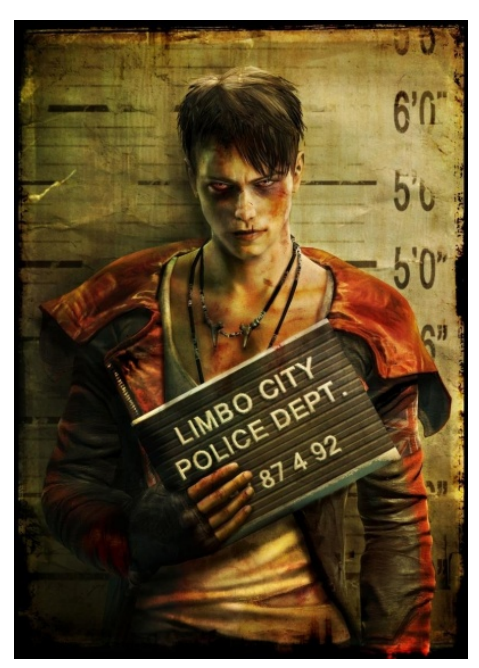
occidental, pese a que los aficionados occidentales del personaje y de la franquicia no opinan lo mismo. Curiosamente, la revista electrónica Siliconera salió a la palestra para hacer una sencilla demostración de lo que las preconcepciones pueden hacer al usuario, animando a sus lectores a mostrarse pacientes dado que el juego seguirá las mismas líneas y el protagonista, pese a todo, sigue siendo el mismo, con tan solo unos retoques menores, tal y como se puede ver en el fotomontaje que se difundió por Internet. 


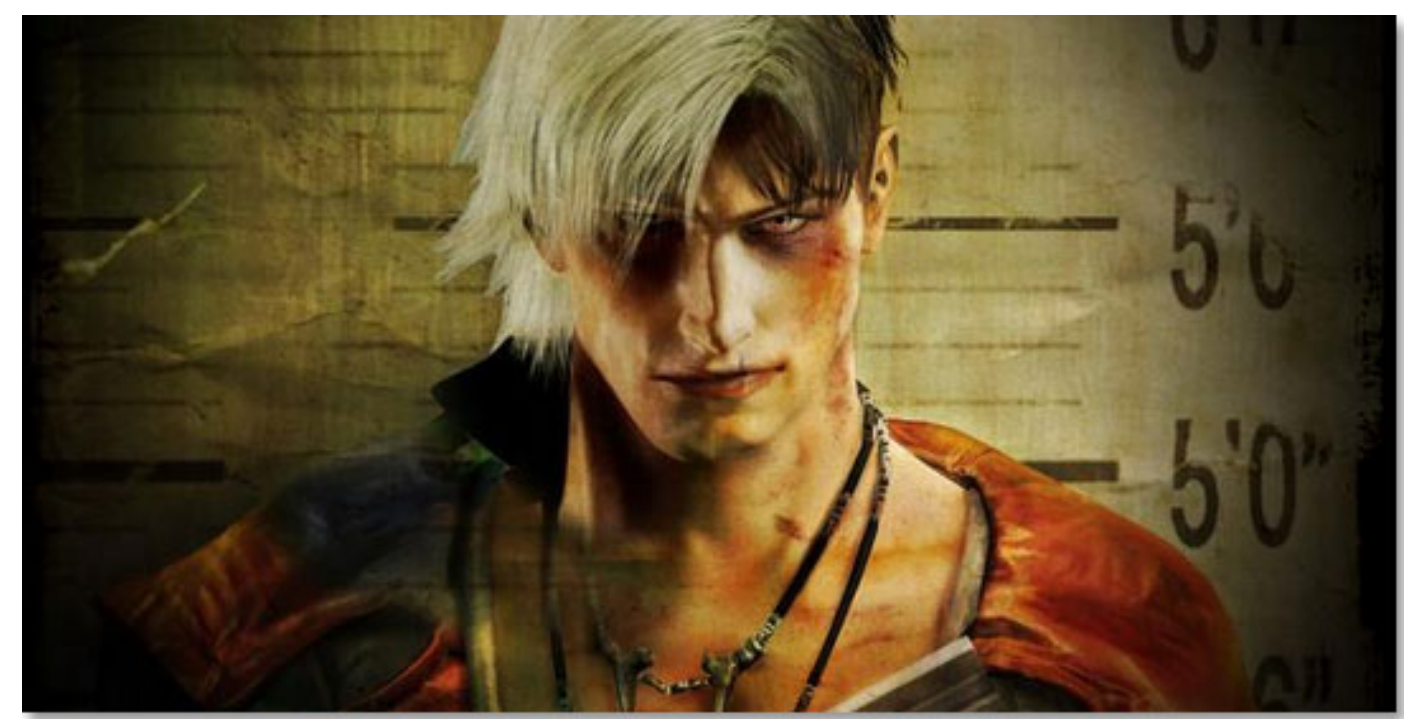

Basta con añadir el pelo blanco para que el tan criticado personaje luzca prácticamente igual que el original, pero es una diferencia lo bastante importante como para parecer algo completamente diferente, solo porque choca con la preconcepción, con la forma de comprender y aceptar la franquicia de Capcom en los diferentes territorios.

Todos estos ejemplos sirven para demostrar que la localización de videojuegos va mucho más allá de los textos y los elementos ingame, como tradicionalmente se tiende a creer, ya que es preciso y fundamental paratraducir carátulas e, incluso, a los propios héroes para así adaptarse a lo que cada tipo de usuario se puede esperar. Es preciso ofrecer en cada mercado aquello que el comprador potencial se espera de cada producto, aunque esto suponga sacrificar algunas vacas sagradas por el bien económico de la compañía y una mayor difusión de un producto que, salvo por modificaciones menores, sigue siendo el mismo en sus pilares básicos.

\section{Conclusión}

El proceso localizador de un videojuego dista mucho de limitarse, única y exclusivamente, a trabajar con el texto. Son infinidad de elementos los que acompañan al texto, ya desde un primer momento en el que el texto está siempre acompañado de una imagen con la que forma una unión irrompible. Localizar implica traducir los textos y adaptar la imagen para que se amolde a las necesidades del producto en un mercado concreto. A veces, durante el proceso localizador, hay que cambiar la música para que se amolde mejor a las necesidades del nuevo mercado; otras veces son los propios héroes los que sufren un proceso modificador en el que se ven obligados a cambiar su propia imagen para adaptarse mejor a lo que el usuario espera encontrarse. E incluso fuera de la pantalla se realizan labores de localización: cambios en las carátulas, adaptación del mando de control, campañas publicitarias... Un videojuego es uno de los productos más complejos que se conocen en el mundo del ocio, hasta tal punto que se expande con infinidad de tentáculos hacia una ingente cantidad de ámbitos que se alejan de lo puramente textual. El profesional de la localización no debe limitarse a afrontar su trabajo como una parte textual independiente, sino que debe estar concienciado de todo lo que el producto presenta al usuario. Él es el nexo último entre el producto y el mercado para el que se está 
localizando y de su labor y comprensión del producto original dependerán, en cierta medida, las opciones de éxito del juego. Un localizador debe estar siempre dispuesto a comprender mejor su producto y a plasmar en él la misma pasión que plasmaron en el original sus creadores. Si no lo hace, la propia localización se quedará coja y no dejará satisfecho a nadie.

Ramón Méndez González

ramonmendez83@gmail.com

Doctor, Grupo de investigación T\&P, Universidade de Vigo, España

\section{Referencias bibliográficas}

CAlvo FerRer, J.R. (2012) Videojuegos y aprendizaje de segundas lenguas. Análisis del videojuego The Conference Interpreter para la mejora de la competencia terminológica. Alicante: Universidad de Alicante, Tesis de doctorado inédita.

EAstin, M.S., APPIAH, O., Y CiCCHIRLlo, V. (2009) «Identification and the influence of cultural stereotyping on postvideogame play hostility», Human Communication Research, 35: 337-356.

GARRIDO VILARIÑO, X. M. (2007) «Ideología y traducción: la paratraducción», Lenguas en contexto, $\mathrm{n}^{\circ} 4$ - Octubre 2007: 52-59.

MÉNDEZ GonZÁLEZ, R. (2010) «La traducción, un factor clave», Meristation. [Online].

Disponible

en: http://www.meristation.com/v3/des_articulo.php?id=cw4b519f8f7bae8\&pic $=$ GEN\&idj $=\& i d p=$. (Consultado el 20/02/2014). . (2011) «Spiderman: Shattered Translation?», en Blog de Ramón Méndez. [Online]. Disponible en: http://paratraduccion.com/rmendez/?p=12. (Consultado el 20/02/2014).

. (2012a) Traducción \& Paratraducción de videojuegos: textualidad y paratextualidad en la traducción audiovisual y multimedia. Vigo: Universidad de Vigo, Tesis de doctorado inédita.

. (2012b) «Cuando los videojuegos son referentes culturales», en Blog de Ramón Méndez. [Online]. Disponible en: http://paratraduccion.com/rmendez/?p=95. (Consultado el 20/02/2014).

. (2012c) «Un día en la vida de un traductor de videojuegos», Mundogamers. [Online]. Disponible en: http://www.mundogamers.com/articuloun_dia_en_la_vida_de_un_traductor_de_videojuegos-pc.89.html. (Consultado el 20/02/2014). 
. (2012d) «Traducir videoxogos dende a paratradución», Viceversa 17-18: 141-158.

. (2013) «Localización de videojuegos: necesidades y posibilidades de la traducción del siglo XXI», en MONTERO, X. [ed.], Traducción para la comunicación internacional: 57-70. Granada: Editorial Comares.

PIXFANS (2009) «La importancia del mando como transmisor de sensaciones», Pixfans. [Online]. Disponible en: http://www.pixfans.com/la-importanciadel-mando-como- transmisor-de-sensaciones (Consultada el 12/04/2012).

YUSTE FRÍAS, J. (2006) «La pareja texto/imagen en la traducción de libros infantiles», en Luna Alonso, A. y S. Montero Küpper [eds.], Tradución e Política editorial de Literatura infantil e xuvenil, Vigo: Servizo de Publicacións da Universidade de Vigo, col. T\&P, n. ${ }^{\circ}$ 2: 267-276.

. (2009) Traducción Intersemiótica. Parte I : La traducción de la pareja texto_imagen, (PDF de la materia del curso de doctorado), Vigo: máster de doctorado T\&P.

. (2012) «Fun for All 1: Videojuegos y paratraducción. Video Game's Translation and Paratranslation», en Blog de Yuste. On y sème à tout vent, Vigo: Blog de Investigación T\&P, 23/03/2012, [Online] 